\title{
Effects of termites on soil cover system performance
}

\author{
S. Lamoureux O'Kane Consultants Inc., Canada
}

M.A. O'Kane O'Kane Consultants Inc., Canada

\begin{abstract}
Little is known regarding the influence of termites on the performance of mine waste cover systems. This paper attempts to qualify the potential effects by reviewing existing termite research and relating it to cover system design and performance. It has been well documented that termites alter soil physically, chemically and hydrologically; however, the results tend to be highly variable. Four key properties relating to long-term cover performance were used to evaluate the effects of termites, namely, soil water characteristics, soil integrity, saturated hydraulic conductivity, and soil chemical characteristics/vegetation. Subterranean foraging holes and galleries created by a wide range of termite species tend to increase the rate of infiltration by a factor of one to three depending on termite activity, soil type, and rainfall intensity. However, the effect of termites on infiltration is typically only significant on soils with low hydraulic conductivity.
\end{abstract}

Termites preferentially select finer textured material for their constructions and in extreme cases have been known to burrow up to $55 \mathrm{~m}$ in search of moist soils. Preferential selection and movement to the surface of finer textured materials could have an effect on soil water characteristics, and physical integrity. In addition, termites could potentially improve conditions for the development of sustainable vegetation by improving nutrient cycling, aeration, and soil moisture. Cover systems with shallow barrier layers are likely the most susceptible to damage by termites. The hydraulic conductivity of barrier layers could be increased; however, the effect has been found to be overshadowed by the presence of extensive vegetation. The potential usage of barrier layer material for termite constructions would be damaging to long-term performance and emphasises the need for an appropriately designed growth medium for protection. Cover systems that utilise the moisture store-and-release concept may very well benefit from termite activity. By improving conditions for the development of a sustainable vegetative system, termites could potentially improve moisture cycling and physical stability. Similar to cover systems with barrier layers, the preferential usage of finer textured material has the potential to reduce homogeneity and create unplanned pathways for water.

Understanding the effects of termites on cover performance and subsequently incorporating them into the design process should increase the over performance of soil covers over the long term. Preliminary termite nest density counts on cover systems may improve modelling efforts if incorporated into the performance modelling process. Current research which examines the chemical, physical, and hydrological effects of termites on soil can be quite variable. Variability makes it difficult to quantify the significance of termite activity on mine waste cover systems. Future research should focus on quantifying termite abundance over the successional life of cover systems for each termite feeding and nesting behaviour to gain a better understanding of their densities and thus the magnitude of their effects on mine waste covers.

\section{Introduction}

The influence of soil macrofauna on the structural, chemical, and hydrological properties of soils has become a source of growing interest to geoscientists and engineers in the field of soil cover system design. Termites have been the subject of research as it is believed their presence on soil cover systems could lead to decreased cover system performance, primarily through macropore formation. Through macropore formation it is thought water may percolate into mine waste more readily as a result of increased net percolation through the cover system. The influence of macropores on infiltration is highly dependent on macropore abundance, which tends to vary between regions and species (Mando et al., 1996; Léonard et 
al., 2004; Dawes, 2010). Therefore, the accurate quantification of macropore infiltration rates is uncommon. Further, infiltration rates are often dependent on the type of measurement conducted (Léonard and Rajot, 2001; Léonard et al., 2004). Simulated experiments often overestimate results while those found naturally may in fact lead to underestimates (Léonard and Rajot, 2001). In arid and semi-arid regions like those found in the Northern Territory of Australia, infiltration caused by macropore formation may in fact be beneficial as soil moisture may increase over longer periods (Elkins et al., 1986; Léonard and Rajot, 2001). Some believe termite establishment should be encouraged as other benefits may be derived from their presence on sites. Their use as a suitable restoration practice has been evaluated in many instances, especially in arid and semi-arid environments where low nutrient environments are common (Mando et al., 1996; Dawes-Gromadzki, 2005). Termites are often associated with the ability to facilitate nutrient cycling and other processes that allow greater vegetation establishment success (Sileshi et al., 2010). Overall, studies express mixed opinions regarding the influence of termites on the structure, chemistry, and hydrology of soils with even less knowledge pertaining to their influence on cover system performance.

This paper attempts to qualify the potential effects of termites on cover system performance by reviewing existing termite research and relating it to cover system design. Emphasis is placed on the arid and semiarid regions of Australia. Termites have been divided into feeding and nesting behaviours in order to better qualify which have the potential to influence cover performance parameters. The effects of termites on cover system performance parameters were evaluated on the basis of changes to soil hydrology, chemistry, and structure in addition to vegetation establishment. An attempt was also made to quantify the number of termite mounds on a cover system in the Northern Territory of Australia since its inception 35 years ago.

\section{Background}

\section{$2.1 \quad$ Mine waste cover systems}

\subsubsection{General cover system objectives}

Variability of mine waste can make it difficult to define cover system objectives which fit all scenarios. Both the chemical and physical properties of mine waste may differ from site to site. For instance, some waste may be dangerously reactive to the point of spontaneous combustion (Waters and O'Kane, 2003), while others may be radiologically contaminated (Reszat et al., 2009). Physical attributes such as susceptibility to erosion, stability, and consolidation can also vary in mine waste and may influence cover system design objectives. However, there are two general design objectives that are common among cover systems for rehabilitation of reactive mine waste; namely, minimisation of both oxygen and water ingress into the waste material.

The effects of termites on cover systems are based on the two aforementioned principle objectives of cover systems. However, it should be noted some cover systems may be designed with other objectives in mind, for example, oxygen consumption and reaction inhibition (INAP, 2009). The consequences of termite activity on these other types of design objectives may or may not be significant, and is considered outside the scope of this paper.

\subsubsection{Types of cover systems}

One key site characteristic which influences the design objectives of cover systems is climate. Termites are largely found in tropical, subtropical, and savannah habitats (Lee and Wood, 1971). Figure 1 shows generalised cover systems that are typically used in varying climate types. For the most part, termites exist within the range of water-shedding and store-and-release covers. In the humid rainforests of tropical and sub-tropical areas termites could exist within the range of water covers (Figure 1). For the purposes of this review, only the effects of termites on water-shedding and store-and-release cover systems are considered. 


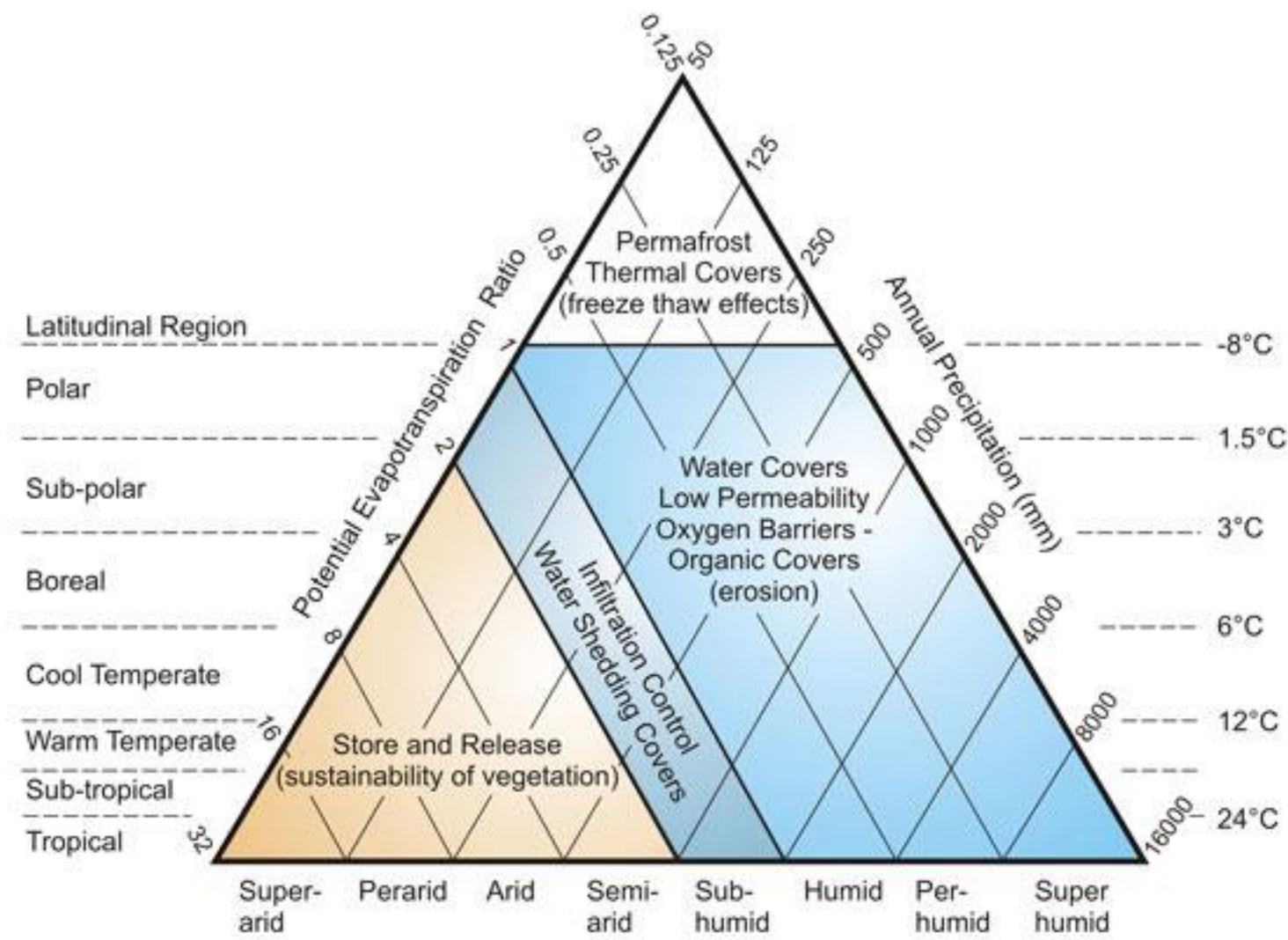

Figure 1 Covers and climate types (from INAP, 2009)

In order to determine the effects termites have on water-shedding and store-and-release cover systems, the purpose and general characteristics of theses covers must be understood. Water-shedding covers aim to reduce infiltration by means of a low hydraulic conductivity (barrier) layer. This layer may promote runoff or the lateral flow of soil water (interflow) in a cover system. A potential secondary objective for the low permeable layer may be to hold water and act as a barrier to oxygen. This can be achieved because although finer textured materials (clays) will typically have a lower hydraulic conductivity, they will also maintain higher moisture content at higher matric suctions. Water-shedding covers are usually constructed with a growth medium overlying the barrier layer. The growth medium serves as protection against physical, chemical, and biological processes that may compromise the integrity of the barrier layer. In addition, as the barrier layer delays downward percolation it allows the growth medium more time to release moisture to the atmosphere (Ayres et al., 2004). Sloping landforms may also be used in conjunction with these layers to promote interflow, thereby further reducing net percolation rates (MEND, 2004).

A moisture store-and-release cover system is designed to maximise the storage of incoming rainfall and then release it during periods of high evaporative demand. The intended result is a near zero net percolation to the underlying waste material (O'Kane et al., 1998). A typical store-and-release cover system will consist of a well-graded material with sufficient storage capacity to accumulate water during rainfall events (MEND, 2004). The thickness of store-and-release cover systems typically ranges from approximately one to four metres. Depending on the quantity of annual rainfall and the storage capacity of the material, store-and-release cover systems will typically be thicker than water-shedding systems. However, at a certain point thicker covers may no longer reduce net percolation because there is a limit to how deep atmospheric forcing can influence pore water, although increased water retention due to cover thickness may help satisfy plant demands.

A healthy and sustainable vegetative cover is also critical to cover systems due to roots which stabilise the soil, and 'pull' water up to be released to the atmosphere through transpiration. In this way, transpiration promotes the cycling of water and therefore the reduction of seepage. The beneficial effect of transpiration 
is especially important to store-and-release systems. The second benefit of vegetation is its ability to maintain the physical integrity of the cover system. One of the most considerable threats to cover systems is the formation of deep gully erosion channels (Ayres et al., 2006). The living plant biomass combined with the decomposing dead plant material provided by the presence of vegetation increases soil stability and reduces erosion (MEND, 2004). Furthermore, in most cases the presence of vegetation on a cover system is aesthetically pleasing and helps create a landform which blends into its natural surroundings.

\section{$2.2 \quad$ Termites}

Ecological dominance has long been displayed by termites due to their eusocial behaviour (Engel et al., 2009). This advanced sociality is characterised by the creation of cast systems where groups of individuals specialise in tasks. The cast system is often divided into reproduction/brood care, foraging, and defence with the latter two offering a competitive advantage when mobilised efficiently, capable of outcompeting other species (Wilson, 1971; Engel et al., 2009). Success has allowed thousands of living species of termites to exist (Engel et al., 2009); therefore, it is useful to group termites based on similarities in behaviour. Feeding and nesting behaviour are two common ways of classifying termites. The feeding habits of termites will help identify a cover system's propensity towards attracting termite populations, and to what extent their influence will be present. The manner in which termites nest is important in determining what termites will likely have the greatest effect on performance of cover systems.

Termites will only colonise a cover system if the right resources are present for them to survive. There are a number of different classification schemes which have been used to group termites in terms of their feeding behaviour. Although in tropical and subtropical ecosystems they are the principal consumers of the most abundant biomolecule on land (cellulose and lignocelluloses) (Engel et al., 2009), feeding behaviour classes can be further subdivided. A number of studies have grouped feeding behaviours into five main classes: grass/litter feeders that consume grassy litter, grass and dung; wood feeders who gorge on dead/live wood in litter or standing form; soil-wood feeders that consume highly decomposed wood at the interface of soil; soil feeders that feed on humified materials within the soil; and polyphagous species who consume a range of organic materials (Dawes-Gromadzki, 2008; Dawes, 2010; Braithwaite et al., 1988; Tayasu et al., 1998; Spain et al., 2010). In general, termite colonisation and survival should only occur if the appropriate feeding resources and environmental conditions are present (Spain et al., 2010). In most instances initial colonisers are species that consume litter as this is the food resource transported onto rehabilitated sites during soil profile reconstruction (Spain et al., 2010). As site evolution occurs over time other feeding resources become available allowing specialised wood and humus feeders to establish onsite through natural dispersal mechanisms, including the winged stage of the termite life cycle (Spain et al., 2010). Some termite species may even be extirpated from rehabilitated sites and replaced by others (Spain et al., 2010) making termite colonisation seem like a successional process.

Termite nesting behaviour is an important consideration when attempting to determine the effect termites might have on cover systems. There are four generally accepted classifications of termite nesting habits: hypogeal (below ground), wood, epigeal (mounds above ground), and arboreal (tree nests) (DawesGromadzki, 2008; Dawes, 2010; Eggleton et al., 2002). Although wood and arboreal nesting termites typically construct foraging/transport tunnels and castings in the soil, the effect of their presence on soil covers will not be as profound as other nesting groups. Conversely, epigeal and especially hypogeal nesting groups would logically have the greatest effects on cover performance through bioturbation due to their direct contact with cover systems. Assuming epigeal and hypogeal termites have the greatest effects on cover performance, they are the focus of this paper. Termite nesting areas are important to discuss as they are the main hub of termite activity.

\section{$3 \quad$ Effects of termites on cover system performance}

Given the objectives of typical mine waste cover systems, long-term performance can be evaluated based on several key properties; these include: the saturated hydraulic conductivity, the soil water characteristic curve (SWCC), and the physical integrity of the cover system (MEND, 2004; INAP, 2003). These properties 
are influenced by many interacting factors which, in terms of termites, will involve their affect on soil hydrology and structure, as well as nutrient cycling and its effect on vegetation and abundance. Defining these properties will aid in determining the effects termites have on cover systems; however, it should be noted the degree of influence each property has on a given cover system is variable. This variability combined with the variability in termite behaviour makes it very difficult to develop definitive results, although an attempt is made in this paper.

\subsection{Soil hydrology modification}

Termites construct systems of galleries and tunnels to give them safe access to food, soil particles, and moisture. Sometimes tunnels and galleries are located within the food itself (wood), while others are used to gain access to greater areas for foraging (Lee and Wood, 1971). Generally three types of subterranean burrows exist. The first are directly under the soil resulting from the construction of sheetings, the second are passages used to leave nests, and the third are burrows that result from the construction of nests (Mando et al., 1996). As long as termites are present, passages directly under the soil are renewed, thus maintaining the contribution of infiltration to soil (Mando et al., 1996). The latter two types of burrows appear to persist on the landscape long after termites have left (Mando et al., 1996). Foraging tunnels and galleries have been found to extend over $35 \mathrm{~m}$ from nests (Darlington, 1982), typically consisting of vertical risers to the surface creating macropores at regular intervals $(0.5-0.75 \mathrm{~m})$ for access to food items (Mando et al., 1996; Léonard and Rajot, 2001; Tschinkel, 2010). These tunnels and galleries are often built with excrement or saliva, which displays adhesive and cementing properties (Greaves, 1962; Lee and Wood, 1971; Udoeyo et al., 2000). As termites create macropores that have different hydrological properties than surrounding soils, it is suggested that termites have an effect on the soil properties governing cover system performance. The creation of macropores has been studied due to its ability to increase soil porosity. Elkins et al. (1986) demonstrated that infiltration rates on sites with termites were much higher at $88.4 \mathrm{~mm} / \mathrm{hr}$ as opposed to sites without termites at $51.3 \mathrm{~mm} / \mathrm{hr}$. Interestingly Léonard and Rajot (2001) noted that at least 30 foraging holes per square metre were necessary for a significant infiltration effect.

Darcy's law through porous media describes the flow of fluid through porous media including soil (Equation 1). Hydraulic conductivity ( $k$ ) describes a soils ability to convey fluid (MEND, 2004).

$$
Q=-k A i
$$

As the energy gradient $(i)$ increases, so does the downward flux of fluid $(Q)$ across an area $(A)$. The hydraulic conductivity $(k)$ varies as a function of saturation. The saturated hydraulic conductivity is the constant conductivity of a soil at saturation. The saturated conductivity of cover materials, therefore, has direct implications on how water infiltrates into a cover system.

The increase in porosity discussed previously is a result of macropore creation through the construction of tunnels and galleries, which has a direct effect on the saturated hydraulic conductivity $\left(\mathrm{k}_{\mathrm{s}}\right)$ of soils. There has been much confusion about how termites effect soil infiltration. One argument is the cementing of surface soil particles by termites using saliva, creation of mounds, and hard surface channels has the ability to reduce infiltration and therefore surface $k_{s}$. Another argument is that the increase in pore space by termites allows water to infiltrate more readily and therefore increase $k_{s}$ (Lee and Wood, 1971). However, recent studies have begun to develop a more clear understanding of the effect termites on $k_{s}$. In unsaturated soils, finer textured materials are the preferential flow path for water. Therefore, macropores become significant only during times of ponding, or high rainfall. Ruan and Illangasekare (1998) developed a model to qualify the relationship between overland flow and macropore infiltration in the vadose zone. It was concluded infiltration is highly sensitive to macroporosity, or the number of macropores, suggesting increased macroporosity caused by termites will increase infiltration. A similar conclusion was reached by Léonard and Rajot (2001) in that increased infiltration into soils due to termites is best thought of as a runoff interception process, whereby an increased number of macropores intercepting runoff leads to an increase in infiltration. The presence of termites was found to increase infiltration by two to three times under natural rainfall over four years (Léonard and Rajot, 2001). Other studies have also attempted to 
quantify the increase in magnitude of infiltration with varying results; an increase of 2.5 in crusted soils and 1.5 under natural conditions was observed through numerical simulations (Mando, 1997). The uncertainty associated with quantifying the magnitude of increasing infiltration is due to unnatural experimental conditions, such as the intensities of rainfall and/or very high termite activities not representative of a natural landscape (Léonard and Rajot, 2001). It is also important to consider the influence of different termite species activity and its variation over time and space for a particular site (Léonard and Rajot, 2001). A species effect may be felt due to the differences in surface macropore diameter. Léonard and Rajot (2001) observed mean macropore diameters of $3.7 \mathrm{~mm}$ and $8.6 \mathrm{~mm}$ with corresponding infiltration capacities of $2-6 \mathrm{~cm}^{3} / \mathrm{s}$ and above $9 \mathrm{~cm}^{3} / \mathrm{s}$ for Odontotermes sp. and M. Subhyalinus, respectively. Hence, the differential macropore diameters linking the soil surface and galleries may result in varying infiltration capacities.

Infiltration is achieved through macropore formation and the destruction of soil crusts (Mando, 1997). However, it was found termites only had a significant effect up until a substantial number of shrubs had colonised the study area. This suggests termites increase infiltration on low $k_{s}$ soils; however, their effect is less pronounced or even negated on soils with high $\mathrm{k}_{\mathrm{s}}$ due to soil structure, vegetation, or other soil organisms. Additionally, reductions in the rate of infiltration through macropores created by termites have been observed during cumulative rainfall events (Mando et al., 1996). Erosion generated by the impact of raindrops is thought to fill the openings of galleries resulting in increased surface runoff and decreased ponding times (Mando et al., 1996). Therefore, the time between rainfall events appears to have an effect on the infiltration capacity of water. Longer time intervals between rainfall events should result in increased infiltration capacity (Mando et al., 1996). Léonard and Rajot (2001) also determined that the effect of runoff is sensitive to macropore location, as some may not be favourable to runoff interception. Macropores supplied with water were mainly those located in low topographical positions (Léonard and Rajot, 2001). Overall, the presence of macropores created by termites increases water storage within the primary rooting zone over the short term (Elkins et al., 1986; Léonard and Rajot, 2001). Termite activity may in fact be beneficial on arid and semi-arid sites by enhancing water availability to vegetation through site evolution.

\subsection{Soil modification}

Bioturbation by termites modifies soil in many different manners. In order to construct nests a significant amount of soil is needed. Ackerman et al. (2007) found termite mounds contained higher proportions of sand and silt sized particles compared to surrounding soils. Jouquet et al. (2002) reported the apparent preference of termites to use finer sized particles from deeper in the soil profile to construct their nests. Tunnelling also aerates the soil and redistributes materials within it (Eggleton and Taylor, 2008). It was estimated that termites brought kaolinite to the surface at a rate of approximately $10 \mathrm{~kg} / \mathrm{ha}$ annually, and that nest material volume amounted up to $5 \mathrm{t} /$ ha from a bauxite area in northern Australia (Eggleton and Taylor, 2008). Another study from north Queensland, Australia, found that the mass of mounds amounted to approximately $20 \mathrm{t} / \mathrm{ha}$ (Holt et al., 1980). Over time the decay of nest scatters materials originating from below the A-horizon onto the soil surface potentially shifting soil characteristics (Eggleton and Taylor, 2008). Although it seems as though different species of termites do not have specific particle size requirements for the construction of their nests, most termites preferentially select clay and silt sized particles (Lee and Wood, 1971). An investigation of soil under termite mounds led to the conclusion that in general termites have the potential to modify soil morphology up to $6.1 \mathrm{~m}$ below mounds not including potentially greater depths away from these mounds (Watson, 1962). It is clear termites are quite active in the upper $1 \mathrm{~m}$; however, it was found they may burrow deeper in search of water or moist soils (Lee and Wood, 1971) and in extreme cases 20-55 m in search of the water table (Lepage et al., 1974; Eggleton and Taylor, 2008). As termites embark in search of moisture they bring a considerable amount of mineral material to the surface to include in their nests, potentially altering soil properties at the surface (Eggleton and Taylor, 2008). The presence and activity of termites in the upper several metres of the soil profile could have profound effects on mine waste cover systems. 
SWCCS describe how the volumetric water content of a soil changes in response to changes in negative pore-water pressure or matric suction (INAP, 2003). The water characteristics of soil are strongly influenced by structure and pore space. Finer textured materials will retain water at higher suctions, while coarser grained materials will drain more readily due to smaller pore spaces (see Figure 2). Termite activity could very well alter the SWCC and therefore have an effect on long-term cover system performance.

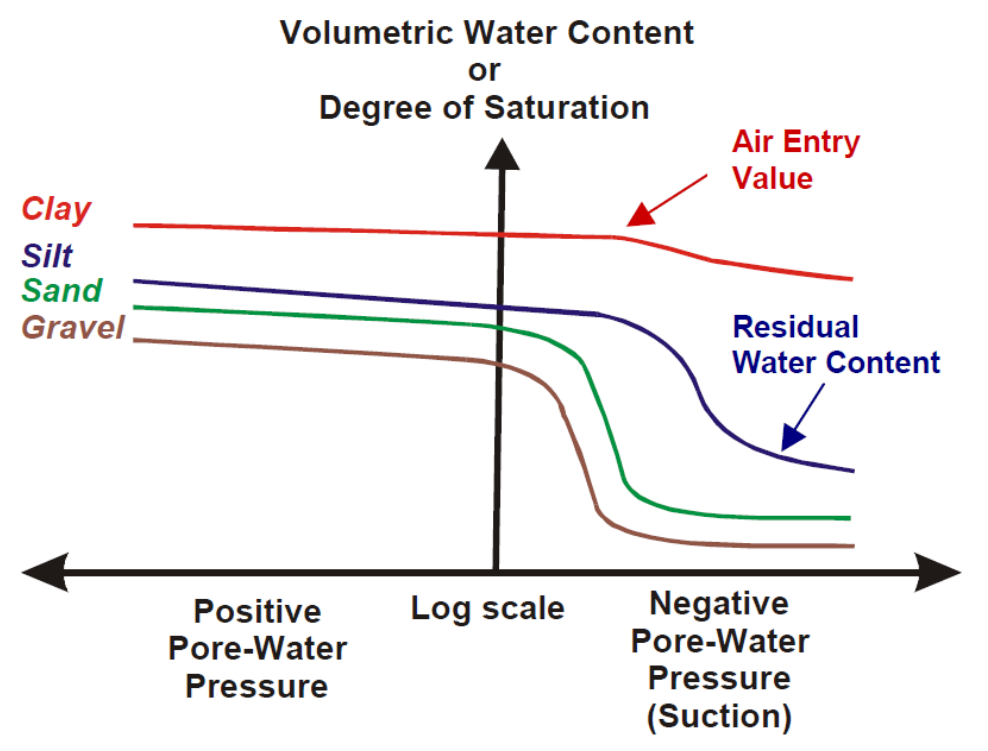

Figure 2 The soil water characteristic curves for different soil types (MEND, 2004)

Tunnelling and nesting behaviour of termites can alter soil horizons (Nye, 1954; Watson, 1965), in addition to soil texture changes due to the preferential selection of finer sized particles for building materials and subsequent erosion of termite structures (Susumu et al., 2009). For instance, superficial fine-textured layers overlying gravelly soil horizons were observed by Nye (1955) and Watson (1960) in Africa. These alterations can bring about changes to soil water characteristics. Figure 2 shows how finer textured materials will retain water at higher suctions. Therefore, by bringing finer materials to the surface, termites may increase the water holding capacity of the surface and near surface cover material. However, the same process may also cause coarse-textured zones within deeper layers of the cover system. This could result in the layer acting as an unintended capillary break by impeding the downward percolation of water, as well as reducing the homogeneity of the cover profile. The alteration of soil texture also could have profound effects on the other key performance properties.

Soil physical integrity is another key parameter of long-term cover system performance. Physical integrity refers to the susceptibility, or resistance, to processes such as erosion, slope movement, and consolidation (MEND, 2004). Analysis of termite effects on physical integrity in this paper is based solely on erosion. A key parameter for soil erodability is soil texture, although the exact effects can be material specific depending on the mineralogy of the smaller fractions such as the dispersivity of clays (MEND, 2004). Erosion is a dynamic process, and it is difficult to determine whether termites strengthen or weaken the physical integrity of a soil. All termites feed on some form of organic or humified material. The presence of organic material and vegetation in a soil improves its resistance to erosion. The act of removing this material through ingestion could have negative effects on the integrity of soils. In addition, the transport of finer grained particles to the surface of a soil may have a negative effect on soil integrity especially if the finer material is dispersive.

\subsection{Nutrient cycling and vegetation}

It has been found termites can improve soil productivity through nutrient cycling, soil structure, and soil water availability. There have been numerous accounts of termite structures containing elevated concentrations of important nutrients such as nitrogen, potassium, phosphorous, magnesium, and calcium (Bruyn, 1990; Bruyn and Conacher, 1995; Sarcinelli et al., 2009), with an overall thought that termite 
colonies act as 'islands of fertility' (Sileshi et al., 2010) in otherwise low fertility environments. For instance, Coventry et al. (1988) found this to occur as termites play a significant part in nutrient cycling, thus facilitating and maintaining plant populations in low-fertility soils. More specifically, a meta-analysis of studies conducted in Africa revealed that termite mounds from the three main families (Macrotermitinae, Termitinae, and Nasutitermitinae) were significantly enriched in carbon (16\%), total nitrogen (42\%), magnesium (154\%), potassium (306\%), calcium (232\%), and clay (75\%) in contrast to the surrounding savannah soil (Sileshi et al., 2010). Nutrients are slowly released back into surrounding soils through the erosion of termite mounds, subsequently creating a patchy mosaic of comparatively more productive areas (Smith and Yeaton, 1998; Eldridge et al., 2001; Masanori and Tooru, 2004). For instance, eroding mounds in the semi-arid, northeastern portion of Queensland, Australia, were estimated to release 2-7 times the amount of nutrients compared to the surrounding low nutrient red and yellow soils (Coventry et al., 1988).

Nutrient cycling by termites and its positive influence on vegetation can occur in several ways. Masanori and Tooru (2004) observed that termites amassed, defended, and gradually released mineralised nitrogen throughout the community. Moreover, wood-feeding termites are capable of fixing atmospheric nitrogen through their gut flora (Lilburn et al., 2001). The consumption of humus by soil-feeding termites also cycles organic matter and mobilises nitrogen (Ji et al., 2000). The accumulation of nitrogen in termite biomass and its subsequent release into the system upon termite death is also thought to be a considerable input of nitrogen into the system although not quantified (Sileshi et al., 2010). In some cases however, it is possible to observe its contribution to nutrient capture by plants. Schaefer and Whitford (1981) observed increases in productivity of shallow rooted plants in the Chihuahuan Desert that coincided with the release of nutrients from dead, subterranean termites that had accumulated within the colonies. Termites that feed on dead wood, litter, and grass also facilitate the cycling of mineral elements and the formation of humus (Sileshi et al., 2010). As these processes occur, nutrients are largely unavailable for plant uptake; however, when the colony dies, rain induced erosion will slowly redistribute material into rooting depths and on the soil surface for plant uptake. Modification of organic matter by termites and its release into soils for subsequent uptake by plants is exemplified by Figure 3 .

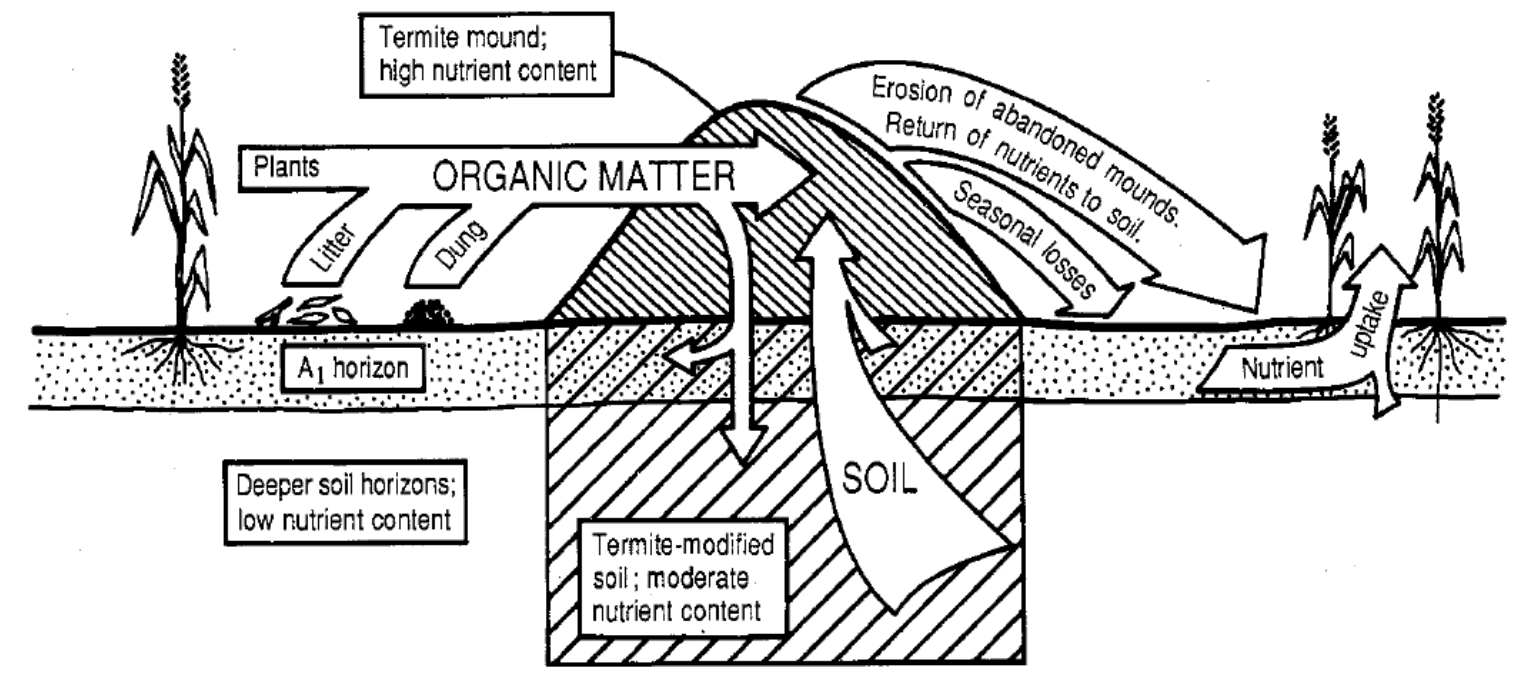

\section{Figure 3 The flow of nutrients and soil materials through termite mounds (Coventry et al., 1988)}

Although the majority of studies focus on nutrient concentrations within the epigeal portion of termite colonies, others have also observed nutrient increases occurring beneath termite mounds. Coventry et al. (1988) determined that each soil chemical property was enriched to at least 1.5 times its concentration compared to soils without the influence of termites. In general, the majority of studies conclude that nutrient cycling by termites plays an important role in sustaining plant growth, especially in harsh landscapes (Coventry et al., 1988; Sileshi et al., 2010). 
The majority of literature concludes soil porosity increases with termite activity, which has beneficial effect on aeration and infiltration with respect to vegetation growth (Lee and Wood, 1971; Mando, 1997). The water available to plants in most cases should improve the development of sustainable vegetation. For instance, mound soil in the Lamto savannah of the Ivory Coast, Africa, contained 33\% more available water during the dry season in the 0-60 cm depth compared to control soils (Konaté et al., 1999). This most likely occurred through the preferential movement of fine soils to the surface by termites, which offer higher moisture retention capacity. Furthermore, macropores and tunnels leading to central nests created by termites may also act as preferential pathways for water flow from broad expanses around nests (Turner, 2006). The higher concentration of water around the nest may thus allow vegetation to establish and remain near termite colonies. The presence of vegetation can also have a significant influence on the physical integrity of soils. Root development and raindrop interception can reduce erosion and increase stability. Therefore, any effect termites may have on the development of a sustainable, vegetated cover system could indirectly benefit the overall integrity and health of the system.

\subsection{Abundance}

It is clear termites influence soil structure, chemistry, and hydrology around them, but to better quantify the magnitude of their effects it is beneficial to gain an idea of their densities within cover systems. Termites are generally found throughout all of Australia, but seem to vary in nesting types and abundance throughout their distribution (see Figure 4). Few studies have attempted to quantify termite nest densities within a given area due to the inherent difficulty; however, some have approximated their numbers. It is important to reiterate that below and aboveground nest building termites most likely have the greatest effect on cover system performance. Hence, this paper focuses on quantifying the density of below and above ground nest building termites.

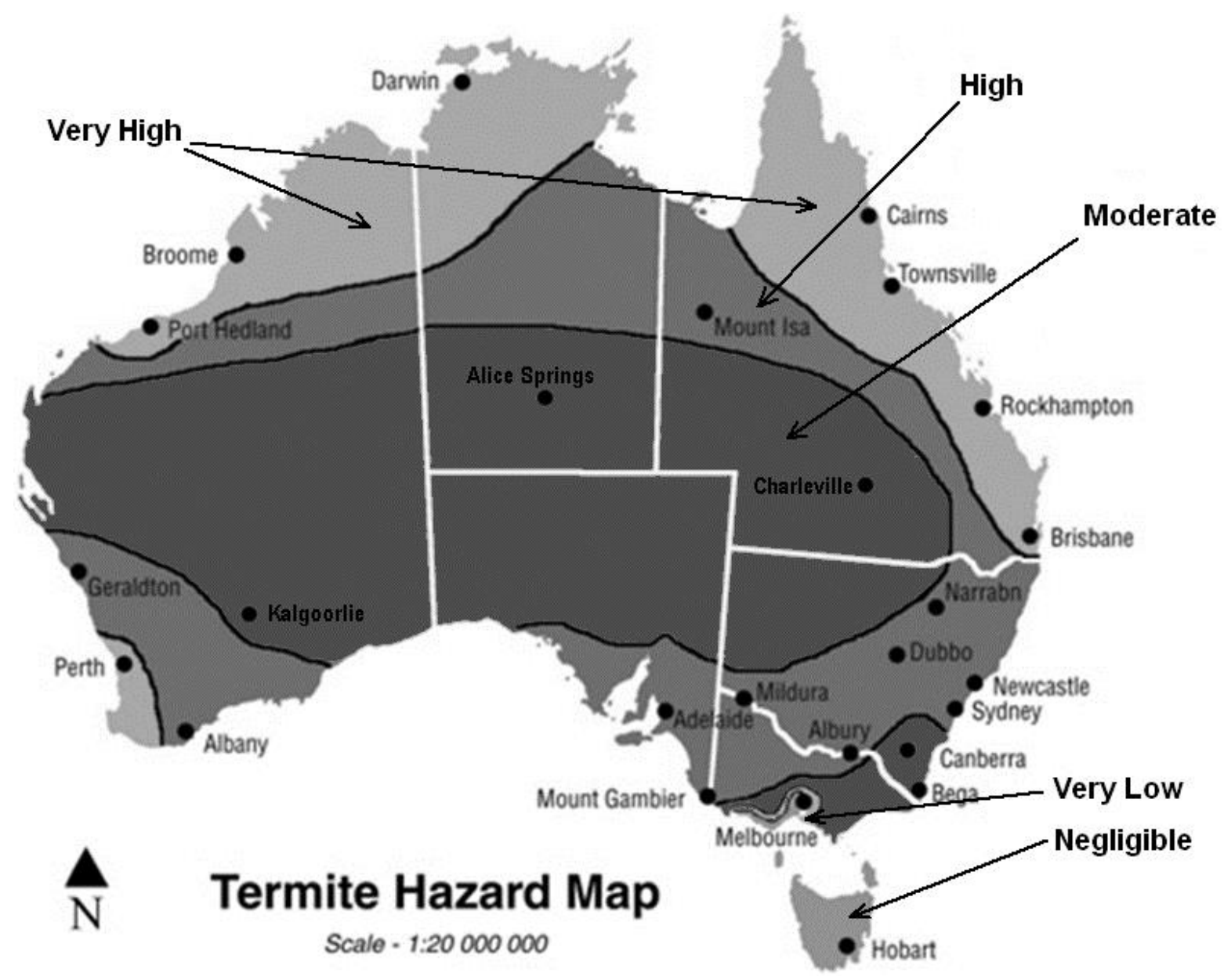

Figure 4 Termite distribution in Australia (Cookson and Trajstman, 2002) 
Epigeal termite mounds were quantified using high-resolution aerial photographs (M. Fawcett, 10 December 2010, written comm.) from the Rum Jungle mine site, Northern Territory, Australia. Photographs of the 35 year old cover system were divided into one hectare quadrants and analysed for termite mounds. This was done by using the actual photo and its negative as an aid by identifying mound shadows as illustrated in Figure 5. The average nest density was approximately 32 nests/ha from the four quadrants analysed. Nest densities from the aerial photographs appear lower than other reported densities in similar areas. Near Charters Towers, North Queensland, Holt et al. (1980) estimated the number of termite mounds to be $283 /$ ha with no significant preference between soil types. Other estimates in Queensland have placed termite mound densities at 350/ha (Watson and Gay, 1970) with rates ranging from 50-100/ha as not uncommon. Lower nest densities from the 35 year old reclaimed site are not representative of an undisturbed site and thus appear much lower. Additionally, if image resolution had been slightly greater the positive identification of mounds may have increased. Lastly, the aerial method does not account for hypogeal termite nests, which appear to be accounted for by other studies using ground identification methods. Subterranean termite densities of the genus Drepanotermes for the same region have been approximated to 1,000 colonies/ha (Watson, 1973).

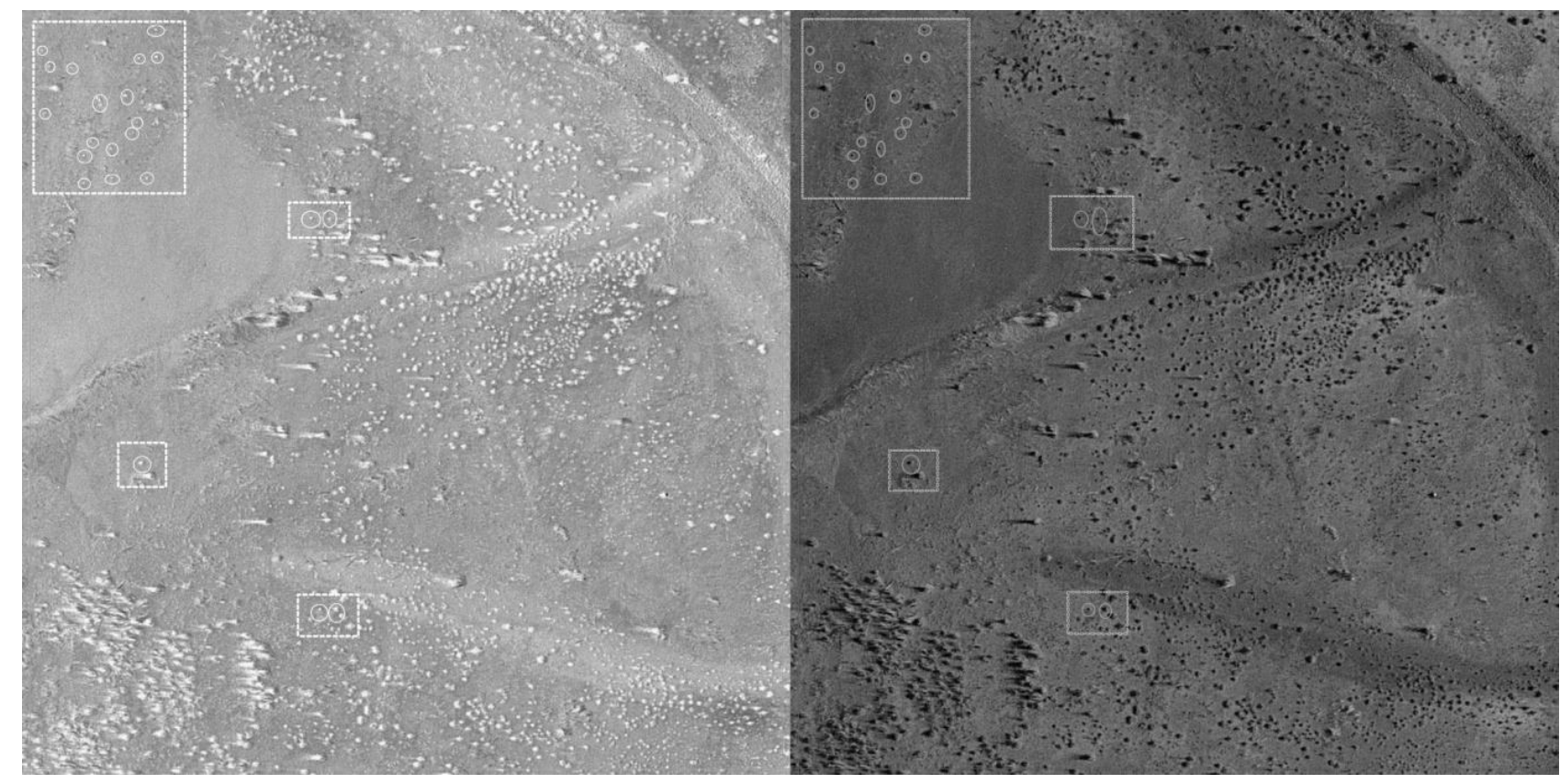

\section{Figure 5 Aerial photograph of the reclaimed Rum Jungle Mine site 35 years after completion with identified epigeal termite mounds (as indicated)}

Although most studies are in agreement, some present dissimilar results. For instance, at the upper limit Roose (1981) estimated a mean termite nest density of 1,300/ha in West Africa, while at the lower limit Lepage (1984) estimated nest densities ranging from 1-37.5 nests/ha in the north east of Ivory Coast, Africa. Discrepancies between studies may exist as some studies include densities of all termite species within an area while others focus on specific termite species. Other studies make the distinction between live and abandoned nests. For example, Lepage (1984) found nest densities of Macrotermes bellicosus ranged from 2.2-37.5/ha for live nests and 1.0-20.2/ha for dead nests. The fact that some nests are abandoned while others are 'live' is not significant in terms of soil cover performance as all nests should exert a similar effect. Differentiation between live and dead nests could, however, affect density counts for a given area, making some studies inadequate for modelling the effect of termites as total nest density is not available. This is especially true if it is considered that some termites may abandon their nests at rates of $165 \pm 66$ nest/ha/yr (Salick et al., 1983). From an ecological standpoint, differences between nest densities could be due to the successional status of a given area. If a site has recently undergone a disturbance, mound building species may not be present as colonisation and survival only tend to occur if the appropriate feeding resources and environmental conditions are present (Spain et al., 2010). Over the 
course of site evolution mound building termites may begin to establish as other feeding resources become available. Therefore, time from disturbance may indeed have an influence on the density of termite mounds present at a particular site. Species and site-specific differences may also play a role in determining the density of nests for a given area.

\section{$4 \quad$ Designing soil covers with consideration for termites}

Although termites pose potentially negative effects, their potentially positive effects may be the overriding factor. Unbeknownst to termites their role as ecosystem engineers may lead to improved cover system performance through indirect processes. Therefore, designing soil covers with consideration for the processes that termites will conduct may improve overall cover system performance. As previously discussed termites have a large influence on soil chemistry, hydrology, and structure in addition to vegetation within the vicinity of their nests. Understanding how these main parameters are altered through termite activity may allow engineers to design cover systems that can negate or even harness the effects of termites on soil cover performance.

Initially considered a negative process, the creation of macropores by termites increases soil porosity. The creation of macropores occurs through the construction of tunnels and galleries, which has a direct affect on the saturated hydraulic conductivity $\left(\mathrm{k}_{\mathrm{s}}\right)$ of the soil. Although covers are designed to limit the amount of water percolation through covers, macropores created by termites are mostly limited to the upper $1 \mathrm{~m}$ of soil and increases water storage within the primary rooting zone (Elkins et al., 1986; Léonard and Rajot, 2001). Any negative effects to cover system performance through macropore formation should be minimal as the majority are contained within the first metre of soil. Termites only appear to have a significant effect on infiltration up until vegetation such as shrubs colonise (Mando, 1997). In some instances, termites have been observed at deeper depths in search of water or moist soils (Lee and Wood, 1971) and in extreme cases 20-55 $\mathrm{m}$ in search of the water table (Lepage et al., 1974; Eggleton and Taylor, 2008). Termites may indeed have a negative effect on cover system performance in some cases through preferential flow of water to mine waste; however, documented cases of these instances are minimal. In an attempt to avoid the exploration of termites into greater depths in search of moisture, soil covers could be designed with adequate thickness in order to retain as much water as possible. Moreover, the application of mulches on degraded landscapes to initiate termite activity by satisfying moisture and nutritional requirements (Elkins et al., 1986; Mando et al., 1996; Dawes-Gromadzki, 2005) has good potential as a restoration practice, which could be included in cover system designs. By satisfying the needs of termites on cover systems, their propensity to explore greater depths may be reduced.

Macropore formation at upper depths should provide benefits to vegetation establishment and sustainability especially in arid and semi-arid landscapes. Within these hot/dry landscapes, evaporation usually far exceeds precipitation leaving much of the soil dry, which hinders vegetation recovery after disturbance. Many studies cite the importance of termites through their ability to survive under high levels of disturbance thus initiating the recovery of soil function (Dawes-Gromadzki, 2005; Dawes, 2010). In arid regions the creation of macropores has an extremely important role in allowing water into crusted soils; without them, much of the moisture would occur as overland flow because infiltration into soils due to termites is best thought of as a runoff interception process (Léonard and Rajot, 2001). Further to macropore formation, the preferential selection of finer sized particles as nest building material by termites will retain water at higher suction due to smaller pore spaces. Finer sized particles nearer to the surface should increase the water holding capacity of soils thus holding more moisture over longer periods. Understanding that finer sized particles will be brought to the surface could potentially be accounted for by particle size distribution analysis and soil-plant-atmosphere numerical simulations, allowing for a more robust prediction of cover system performance. In any case, moisture enhancement provided by finer sized particles should aid vegetation recovery on disturbed landscapes especially in hot/dry regions. The act of bringing new soils to the surface should also facilitate the recovery of vegetation through increased nutrient availability. Furthermore, as termites breakdown organic matter they make nutrients available to vegetation. Vegetation establishment on site should improve the physical integrity of cover systems as 
living and dead plant material increase soil stability and reduce erosion rates. Reductions in erosion should also be reduced through raindrop interception by vegetation.

Understanding the effects of termites on cover system performance and subsequently incorporating them into the design process should increase the overall performance of soil covers over the long term. Termites are distributed across Australia (Figure 4) and as such, will be a part of disturbed site recovery on almost every occasion in one capacity or another. Preliminary termite nest density counts on cover systems may improve numerical modelling efforts if incorporated into the design phase. However, future research should focus on quantifying termite abundance over the successional life of cover systems for each termite feeding and nesting behaviour.

\section{Conclusion}

Water-shedding cover systems are built with the intention of maximising runoff while minimising infiltration by means of a barrier layer. Clearly, a desirable characteristic of this type of cover system is to maintain a low $k_{s}$ layer within the system. If the low $k_{s}$ layer is located at a shallow depth within the profile it could be susceptible to termite activity, effectively increasing its permeability and reducing performance through increased overall net percolation. However, it is anticipated if termites were to have a significant effect on such a cover system, then the cover would ultimately be subject to the same detrimental effects from vegetation and associated root development. In addition, low permeability layers constructed with fine textured materials could be selectively chosen as sources of material for termite constructions. As the finer material is transported to the surface, the low $\mathrm{k}_{\mathrm{s}}$ layer could be compromised. Finally, in arid climates, termites may find the barrier layer to be a good provider of moist soil. A potential exists for termites to negatively affect long-term performance of water-shedding cover systems. It is likely, however, as a low permeable layer is protected by increasingly thick growth mediums, its susceptibility to damage by termites and vegetation will be reduced. This analysis further emphasises the importance of a properly designed growth medium as suggested by Ayres et al. (2004).

Moisture store-and-release cover systems are designed to store rainfall during periods of high rainfall for release during periods of high evaporative potential. Perhaps a negative effect termites could have on a store-and-release system is the introduction of zones of coarse and fine material, which would reduce the desirable well-graded particle size distribution of the cover profile. However, this effect is much too variable to offer any definite conclusions. A critical component of store-and-release systems is vegetation. In this case, an increased $k_{s}$ caused by termites does not compromise the system because their effect will eventually be negated by the development of vegetation. The presence of termites could actually be beneficial by improving nutrient cycling and helping to create a sustainable eco-system on the surface of the cover system and in turn, improving moisture cycling and physical stability. If termites were encouraged to establish on such a cover system using mulches (Mando, 1997), they may expedite the development of vegetation by increasing soil water availability.

\section{References}

Ackerman, I.L., Teixeira, W.G., Riha, S.J., Lehmann, J. and Fernandes, E.C. (2007) The impact of mound-building termites on surface soil properties in a secondary forest of Central Amazonia, Applied Soil Ecology, Vol. 37, pp. 267-276.

Ayres, B.K., O'Kane, M. and Barbour, L.S. (2004) Issues for consideration when designing a growth medium layer for a reactive mine waste cover system, in Proceedings of the 11th International Conference on Tailings and Mine Waste, Vail, Colorado.

Ayres, B., Dobchuk, B., Christensen, D., O'Kane, M. and Fawcett, M. (2006) Incorporation of natural slope features into the design of final landforms for waste rock stockpiles, 7th International Conference on Acid Rock Drainage (ICARD), St. Louis, Montana: American Society of Mining and Reclamation.

Braithwaite, R.W., Miller, L. and Wood, J.T. (1988) The structure of termite communities in the Australian tropics, Australian Journal of Ecology, Vol. 13, pp. 375-391.

Bruyn, L.A. (1990) The role of termites and ants in soil modification: A review, Australian Journal of Soil Research, Vol. 28, pp. 55-93.

Bruyn, L.A. and Conacher, A.J. (1995) Soil modification by termites in the central wheatbelt of Australia, Australian Journal of Soil Research, Vol. 33, pp. 179-193. 
Cookson, L.J. and Trajstman, A.C. (2002) Termite survey and hazard mapping, CSIRO FFP Technical Report No. 137, CSIRO Forestry and Forest Products, Clayton South.

Coventry, R.J., Holt, J.A. and Sinclair, D.F. (1988) Nutrient cycling by mound-building termites in low-fertility soils of semi-arid tropical Australia, Australian Journal of Soil Research, Vol. 26, pp. 375-390.

Darlington, J.P. (1982) The underground passages and storage pits used in foraging by a nest of the termite Macrotermes michaelseni in Kajiado, Kenya, The Zoological Society of London, Vol. 198, pp. 237-247.

Dawes, T.Z. (2010) Impacts of habitat disturbance on termites and soil water storage in a tropical Australian savannah, Pedobiologia, Vol. 53, pp. 241-246.

Dawes-Gromadzki, T.Z. (2005) Bugs beneath the surface: the functional significance of soil macro invertebrates to landscape heath in Australia's tropical savannas, Insect Science, Vol. 12, pp. 307-312.

Dawes-Gromadzki, T.Z. (2008) Abundance and diversity of termites in a savannah woodland reserve in tropical Australia, Australian Journal of Entomology, Vol. 47, pp. 307-314.

Eggleton, P., Davies, R.G., Connetable, S., Bignell, D.E. and Rouland, C. (2002) The termites of the Mayombe Forest Reserve, Congo (Brazzaville): transect sampling reveals an extremely high diversity of ground-nesting soil feeders, Journal of Natural History, Vol. 36, pp. 1239-1246.

Eggleton, R.A. and Taylor, G. (2008) Effects of some macrobiota on the Weipa Bauxite, northern Australia, Australian Journal of Earth Sciences, Vol. 55, pp. S71-S82.

Eldridge, D.J., Lepage, M., Bryannah, M.A. and Ouedraogo, P. (2001) Soil biota in banded landscapes, in Banded vegetation patterning in arid and semi-arid environments: ecological processes and consequences for management, D.J. Tongway, C. Valentin and J. Sergieri (eds), Springer-Verlag, New York, USA, pp. 105-131.

Elkins, N.Z., Sabol, G.V., Ward, T.J. and Whitford, W.G. (1986) The influence of subterranean termites on the hydrological characteristics of a Chihuahuan desert ecosystem, Oecologia, Vol. 68, pp. 521-528.

Engel, M.S., Grimaldi, D.A. and Krishna, K. (2009) Termites (Isoptera): Their Phylogeny, Classification and Rise to Ecological Doninance, American Museum Novitates, Vol. 3650, pp. 1-27.

Greaves, T. (1962) Studies of foraging galleries and the invasion of living trees by Coptotermes acinaciformis and C. brunneus, Australian Journal of Zoology, Vol. 10(4), pp. 630-651.

Holt, J.A., Coventry, R.J. and Sinclair, D.F. (1980) Some aspects of the biology and pedological significance of mound-building termites in a red and yellow earth landscape near Charters Towers, north Queensland, Australian Journal of Soil Research, Vol. 18, pp. 97-109.

INAP (2003) International Network for Acid Prevention. Evaluation of the long-term performance of dry cover systems, final report, Prepared by O'Kane Consultants Inc., Report No. 684-02, March.

INAP (2009) International Network for Acid Prevention. Global Acid Rock Drainage Guide (GARD Guide), Retrieved April 2010, from http://www.gardguide.com/

Ji, R., Kappler, A. and Brune, A. (2000) Transformation and mineralization of synthetic ${ }^{14} \mathrm{C}$-labeled humic model compounds by soilfeeding termites, Soil Biology and Biochemistry, Vol. 32, pp. 1281-1291.

Jouquet, P., Lepage, M. and Velde, B. (2002) Termite soil preferences and particle selections: strategies related to ecological requirements, Insects Sociaux, Vol. 49, pp. 1-7.

Konaté, S., Le Roux, X., Tessier, D. and Lepage, M. (1999) Influence of large termitaria on soil characteristics, soil water regime and tree leaf shedding pattern in a west African savannah, Plant Soil, Vol. 206, pp. 47-60.

Lee, K.E. and Wood, T.G. (1971) Termites and Soils, Cornell University: Academic Press.

Léonard, J. and Rajot, J.L. (2001) Influence of termites on runoff and infiltration: Quantification and analysis, Geoderma, Vol. 104, pp. 17-40.

Léonard, J., Perrier, J.L. and Rajot, J.L. (2004) Biological macropores effect on runoff and infiltration: A combined experimental and modelling approach, Agriculture, Ecosystems and Environment, Vol. 104, pp. 277-285.

Lepage, M. (1984) Distribution, Density and Evolution of Macrotermes bellicosus Nests (Isoptera: Macrotermitinae) in the NorthEast of Ivory Coast, Journal of Animal Ecology, Vol. 53(1), pp. 107-117.

Lepage, M., Morel, G. and Resplendino, C. (1974) Découverte de galeries de Termites atteignant la nappe phréatique profonde dans le Nord du Sénégal, Comptes Rendus de l’Académie des Sciences, Vol. 278, pp. 1855-1858.

Lilburn, T.G., Kim, K.S., Ostrom, N.E., Byzek, K.R., Leadbetter, J.R. and Breznak, J.A. (2001) Nitrogen fixation by symbiotic and freeliving spirochetes, Science, Vol. 292, pp. 2495-2498.

Mando, A. (1997) Effect of termites and mulch on the physical rehabilitation of the structurally crusted soils in the sahel, Land Degredation and Development, Vol. 8, pp. 269-278.

Mando, A., Stroosnijder, L. and Brussaard, L. (1996) Effects of termites on infiltration into crusted soil, Geoderma, Vol. 74, pp. 107-113.

Masanori, T. and Tooru, A. (2004) Soil nutrient loss caused by intensive land use and the retention of nutrients inside termite mounds in Niger, Africa, Japanese Journal of Ecology, Vol. 54, pp. 117-124.

MEND (2004) Mine Environment Neutral Drainage. Design, Construction and Performance of Cover Systems for Waste Rock and Tailings.

Nye, P.H. (1954) Some soil-forming processes in the humid tropics, European Journal of Soil Science, Vol. 5(1), pp. 7-21.

Nye, P.H. (1955) Some soil forming processes in the humid tropics, IV, The action of soil fauna, Journal of Soil Science, Vol. 6, pp. 73-83.

O'Kane, M., Porterfield, D., Haug, M.D. and Endersby, M. (1998) The Design and Implementation of the Field Test Plots at BHP Iron Ore, Mt. Whaleback - A Soil Cover System for an Arid Climate, 1998 SME Annual Meeting and Exhibit, Orlando, Florida. 
Reszat, T.R., Balding, G. and Fawcett, M. (2009) Remediation of small scale uranium activities in the South Alligator Valley, Kakadu National Park, in Proceedings Fourth International Conference on Mine Closure (Mine Closure 2009), A.B. Fourie and M. Tibbett (eds), 9-11 September 2009, Perth, Australia, Australian Centre for Geomechanics, Perth, pp. 213-228.

Roose, E. (1981) Dynamique actuelle de sols ferrallitiques et ferrugineux tropicaux d'Afrique occidentale, Étude expérimentale des transferts hydrologiques et biologiques de matières sous végétations naturelles ou cultivées, Thèse de Doctorat d'Etat ès Sciences, Université d’Orléans, U.E.R. de Sciences fondamentales et appliquées, Trav. et Doc. ORSTOM, no. 130, Paris.

Ruan, H. and Illangasekare, T.H. (1998) A model to couple overland flow and infiltration into macroporous, Journal of Hydrology, Vol. 210, pp. 116-127.

Salick, J., Herrera, R. and Jordan, S.F. (1983) Termitaria: Nutrient Patchiness in Nutrient Deficient Rain Forests, Biotropical, Vol. 15(1), pp. 1-7.

Sarcinelli, T.S., Schaefer, C.E.G.R., Lynch, L.D., Arato, H.D., Viana, J.H.M., de Albuquerque, M.R. and Gonçalves, T.T. (2009) Chemical, physical and micromorphological properties of termite mounds and adjacent soils along a toposequence in Zona da Mata, Minas Gerais State, Brazil, Catena, Vol. 76(2), pp. 107-113.

Schaefer, D.A. and Whitford,W.G. (1981) Nutrient cycling by the subterranean termite Gnathamitermes tubiformans in a Chihuahuan desert ecosystem, Oecologia, Vol. 48, pp. 277-283.

Sileshi, G.W., Arshad, M.A., Konaté, S. and Nkunika, P.O.Y. (2010) Termite-induced heterogeneity in Africa savannah vegetation: mechanisms and patterns, Journal of Vegetation Science, Vol. 21, pp. 923-937.

Smith, F.R. and Yeaton, R.I. (1998) Disturbance by the mound-building termite, Trinervitermes trinervoides and vegetation patch dynamics in a semi-arid, southern African grassland, Plant Ecology, Vol. 137, pp. 41-53.

Spain, A.H., Hinz, D. and Tibbett, M. (2010) Colonisation of rehabilitated lands by termites (Dictyoptera), Rio Tinto Alcan Gove bauxite mine, Northern Territory, Australia, in Proceedings Fifth International Conference on Mine Closure (Mine Closure 2010), A.B. Fourie, M. Tibbett and J. Wiertz (eds), 23-26 November 2010, Viña del Mar, Chile, Australian Centre for Geomechanics, Perth, pp. 437-448.

Susumu, A.S., Yamamoto, S. and Wakatsuki, T. (2009) Soil-particle selection by the mound-building termite Macrotermes bellicosus on a sandy loam soil catena in a Nigerian tropical savannah, Journal of Tropical Ecology, Vol. 25, pp. 449-452.

Tayasu, I., Inoue, T., Miller, L.R., Sugimoto, A., Takeichi, S. and Abe, T. (1998) Confirmation of soil-feeding termites (Isoptera; Termitidae; Termitinae) in Australia using stable isotope ratios, Functional Ecology, Vol. 12, pp. 536-542.

Tschinkel, W.R. (2010) The foraging tunnel system of the Namibian Desert termite, Baucaliotermes hainesi, Journal of Insect Science, Vol. 10(65), pp. 1-17.

Turner, J.S. (2006) Termites as mediators of the water economy of arid savannah ecosystems, in Dryland ecohydrology, P. D'Odorico and A. Porporato (eds), Springer, Dordrecht, NL, pp. 303-313.

Udoeyo, F.F., Cassidy, A.O. and Jajere, S. (2000) Mound soil as construction material, Journal of Materials in Civil Engineering, pp. 205-211.

Waters, P. and O'Kane, M. (July 2003) Mining and Storage of Reactive Shale at BHP Billiton's Mt Whaleback Mine, in Proceedings 6th International Conference for Acid Rock Drainage, Cairns, QLD, Australia.

Watson, J.A.L. and Gay, F.J. (1970) The role of grass-eating termites in the degradation of a mulga ecosystem, Search 1:43.

Watson, J.P. (1960) Some observations on soil horizons and insect activity in granite soils, in Proceedings 1st Federal Science Congress, Rhodesia, Nyasaland, pp. 271-276.

Watson, J.P. (1962) The soil below a termite mound, European Journal of Soil Science, Vol. 13(1), pp. 46-59.

Watson, J.P. (1965) A soil catena on granite in southern Rhodesia, European Journal of Soil Science, Vol. 16(1), pp. $158-169$.

Watson, J.P. (1973) Termites in Mulga Lands, Tropical Grasslands, Vol. 7(1), pp. 121-126.

Wilson, E.O. (1971) Insect Societies, Cambridge, MA: Belknap Press, 584 p. 